\title{
Processing and characterization of poly(lactic acid) based bioactive composites for biomedical scaffold application
}

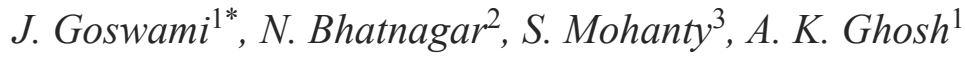 \\ ${ }^{1}$ Centre for Polymer Science \& Engineering, Indian Institute of Technology Delhi 110016 New Delhi, India \\ ${ }^{2}$ Mechanical Engineering Department, Indian Institute of Technology Delhi 110016 New Delhi, India \\ ${ }^{3}$ Stem Cell Facility, All India Institute of Medical Sciences 110029 New Delhi, India
}

Received 8 April 2013; accepted in revised form 1 June 2013

\begin{abstract}
The current study focuses on three-components material systems (poly(lactic acid) (PLA), poly( $\varepsilon$-caprolactone) (PCL) and wollastonite (W)) in view of possible application a biomedical scaffold constructs. Melt extruded PLA/PCL/W composites (PLCL15, PLCLW1, PLCLW4, PLCLW8 containing 0, 1, 4, 8 phr filler respectively) are batch foamed using compressed $\mathrm{CO}_{2}$ and the porous foams are studied for in vitro biocompatibility by seeding osteoblast cells. SEM images of the unfoamed polymers show immiscibility in all compositions. Materials have been tested under compressive load using dry and wet conditions (using phosphate buffered saline at $\mathrm{pH}$ 7.4) for in vitro study. Contact angle measurement shows enhanced hydrophilicity in the composites changing from $80^{\circ}$ in PLCL15 to $72^{\circ}$ in PLCLW8. The foams are found to be microcellular $(5-8 \mu \mathrm{m})$ in morphology showing quite uniform pore distribution in the composites. The prepared foams, when studied as scaffold constructs, show osteoblast cell attachment and proliferation over the incubation period of 7 days. As expected, PLCLW8 containing highest amount of $\mathrm{CaSiO}_{3}$ supported maximum cell growth on its surface as visible from MTT assay data and SEM scans.
\end{abstract}

Keywords: biopolymers, composites, hydrophilicity, foams, cell viability

\section{Introduction}

The use of polymers for biomedical applications is an emerging field gaining maximum attention from researchers across the world due to their advantages as given below;

- Mitigating the need for second surgery for want of autogeneous bone grafts,

- Formation of load bearing bones without any stress shielding effect and

- Degradation of the scaffold with time into nontoxic byproducts as the osteoblasts grow into bone tissues.

These are some of the deciding factors for polymeric clinical devices as against allografting, autografting and xenografting. The selection of the polymers to be used as biomedical implant needs to be done carefully, based on the following criteria $[1,2]$ :

- The compositional resemblance and comparable mechanical properties of the polymer with the host tissue,

- Processability and fabricability with defined reproducibility along with sterilizability and

- Modulation of degradation profile of the polymer as per the requirement of the intended application.

The design of the biomaterial with requisite characteristics depends exclusively on the properties of the host tissue. The soft and hard tissues vary extensively in their intrinsic material properties and the mechanical properties of these tissues are listed in Table 1.

\footnotetext{
*Corresponding author, e-mail: jutikagoswami@gmail.com (c) BME-PT
} 
Table 1. Biomechanical properties of human body tissues [1,2]

\begin{tabular}{|l|c|c|c|c|c|}
\hline \multicolumn{1}{|c|}{ Type of tissue } & $\begin{array}{c}\text { Young's modulus } \\
{[\mathbf{M P a}]}\end{array}$ & $\begin{array}{c}\text { Tensile strength } \\
{[\mathbf{M P a}]}\end{array}$ & $\begin{array}{c}\text { Strain at break } \\
{[\%]}\end{array}$ & $\begin{array}{c}\text { Density } \\
{[\mathbf{g} / \mathbf{c c}]}\end{array}$ & \multicolumn{1}{|c|}{ Composition } \\
\hline $\begin{array}{l}\text { Soft tissue } \\
\text { (articular cartilage) }\end{array}$ & 10.5 & 27.5 & - & - & - \\
\hline $\begin{array}{l}\text { Hard tissue } \\
\text { (cortical bone) }\end{array}$ & $(14-20) \cdot 10^{3}$ & $50-150$ & $1-3$ & $1.8-2.2^{*}$ & $\begin{array}{l}\text { Collagen (20\%), hydroxyapatite (cal- } \\
\text { cium phosphate) (60\%), others (20\%) }\end{array}$ \\
\hline $\begin{array}{l}\text { Hard tissue } \\
\text { (cancellous bone) }\end{array}$ & $(0.05-0.5) \cdot 10^{3}$ & $10-20$ & $5-7$ & $0.1-1.0$ & $\begin{array}{l}\text { Same as hard tissue with higher } \\
\text { porosity }\end{array}$ \\
\hline
\end{tabular}

"apparent density. True density of cortical bone is $18-20 \mathrm{~g} / \mathrm{cc}$

Poly(lactic acid) (PLA), termed as 'green biopolymer', is gaining priority over other biopolymers for biomedical applications due to its property relevance to the biological tissues in terms of biodegradability, biocompatibility and its availability from natural resources. PLA has been the first biodegradable polymer to obtain Food and Drug Administration (FDA), USA approval for clinical applications. It has been used as sutures for long, recently as cardio vascular stents and bone graft scaffolds that degrade by both enzymatic and non-enzymatic way into lactic acid under physiological environment [3-9]. But the disadvantage of PLA is its brittleness and lower thermal stability due to which its melt processability has been a great concern [10-12]. Studies have been done to get away with these difficulties by methods like copolymerization, blending with other polymers, and plasticization. Poly $(\varepsilon-$ caprolactone) (PCL) is another FDA approved synthetic biodegradable aliphatic polyester that is produced via petrochemical route. It is a lower modulus thermoplastic elastomer with higher toughness at room temperature (glass transition temperature, $\left.T_{\mathrm{g}}:(-) 60^{\circ} \mathrm{C}\right)$ as compared to PLA $\left(T_{\mathrm{g}}: 60^{\circ} \mathrm{C}\right)[13]$. Melt blending of PLA with PCL is expected to improve the processability of PLA as it is thermally more stable.

However, there are limitations of the organic polymeric scaffolds originating with the release of acidic by-products that causes inflammation inside the human body and the lack of adhesion with the bone cells due to differences in their compositional properties [14]. The addition of a bioactive material either osteoinductive or osteoconductive to the polymeric system gives an added advantage of tissue adhesion with the organic phase. Different biomaterials like hydroxyapatite, bioactive glasses, and glass-ceramics having bonelike mineral compositions are being added to the polymers so as to make the tissue regeneration process faster by improving bone bonding in vivo [15-17]. It is reported that $\mathrm{CaO}$ and $\mathrm{SiO}_{2}$ are two main bone bonding components for formation of apatite layer at the damaged tissue site $[2,18]$. Wollastonite (W), containing $\mathrm{CaO}-\mathrm{SiO}_{2}$, is a highly potential bioactive filler to prepare biodegradable composites for tissue engineering applications, and its potentiality for use in medical devices can be well understood from the overwhelming response of the researchers in recent years [19-21]. This high aspect ratio acicular material can help the implanted organic scaffold to bond with the bone because of the chemical similarity with the bone minerals while maintaining mechanical integrity under physiological environment. Another advantage of using this filler is that the alkaline degradation products of the mineral help in neutralizing acidic by-products of the biopolymers thereby reducing inflammation. Thus polymeric scaffold prepared from composites based on PLA, PCL and W is expected to provide improved mechanical as well as physiological activity by way of initially reinforcing the polymer blend matrix and later as a bioinitiator.

A polymeric scaffold needs to be a porous network structure with well-defined porosity and morphology. Scaffolds are prepared by different processes such as electrospinning, porogen leaching, solvent casting, foaming using chemical blowing agent (CBA) and physical blowing agents (PBA), rapid prototyping etc. [22-24]. But use of any solvent or CBA may be detrimental for a scaffold to be used in vivo due to traces of contamination. Supercritical carbon-di-oxide $\left(\mathrm{ScCO}_{2}\right)$ as PBA has been used extensively for this purpose due to its inertness, environmental friendly nature and easy availability [25-27]. The current study involves solid state batch foaming of the PLA/PCL/W composites so as to develop porous scaffolds using compressed $\mathrm{CO}_{2}$. Compressed $\mathrm{CO}_{2}$ acts as plasticizer or solvent to a polymer system that reduces glass transition temperature $\left(T_{\mathrm{g}}\right)$ causing enhanced self-diffusion of the 
solvent increasing its solubility further [28]. Interaction of $\mathrm{CO}_{2}$ and PLA has been established by Fourier transform infrared (FTIR) studies indicating better solubility into this polymer as compared with other physical blowing agents such as $\mathrm{N}_{2}$ and this improved solubility implies better foamability of the concerned polymer [29, 30].

Diffusion driven nucleation in a heterogeneous system such as PLA/PCL/W is favored as compared to that of a homogeneous one (neat PLA) because the activation energy needed for solvent dissolution is lowered at the interphases. The effect of wetting angle at the interface has been explained in heterogeneous nucleation theory [31]. PCL as immiscible domains and $\mathrm{W}$ as inorganic filler, both contribute towards inhomogeneity in the PLA matrix, thereby, enhancing the effect of wetting angle for $\mathrm{CO}_{2}$ diffusion. In vitro bioactivity of wollastonite has already been reported as PLA/W and PCL/W composite systems showing mineralization when studied using simulated body fluid (SBF) $[14,23]$. Thus, the presence of wollastonite helps in osteoblast cell growth in similar way like that of hydroxyapatite (HA), the main mineral component in bone tissues [32].

The focus of the present study is to develop PLA/ $\mathrm{PCL} /$ wollastonite composites as porous constructs and to analyze the scaffolds for bio-suitability by seeding osteoblast cells onto them in an in vitro study. The suitability of the material system developed for this purpose depends exclusively on the cell adhesion response and improvement in mechanical properties could be an added advantage.

\section{Experimental}

\subsection{Raw materials}

Poly(lactic acid) (ESUNTM A-1001) and Poly( $\varepsilon-$ caprolactone) (CAPA-6800) were supplied by Shenzhen BrightChina Industrial Co. Ltd, China and Perstorp Chemicals, UK respectively. The density and melt index (MFI) of PLA were specified as $1.25\left(\mathrm{~g} / \mathrm{cc}, 21.5^{\circ} \mathrm{C}\right)$ and $10-15\left(\mathrm{~g} / 10 \mathrm{~min}, 190^{\circ} \mathrm{C}\right.$, $2.16 \mathrm{~kg}$, ASTM D1238) respectively. The molecular weight and MFI for PCL were $80000 \mathrm{~g} / \mathrm{mol}$ and $3\left(\mathrm{~g} / 10 \mathrm{~min}\right.$ at $160^{\circ} \mathrm{C}, 2.16 \mathrm{~kg}, \mathrm{ASTM}$ D1238) respectively. Wollastonite (Kemolit K-1010, Wolkem India Limited, Udaipur, India) in the powder form was used as filler in this study.

\subsection{Material preparation}

The blend composition with PLA/PCL ratio of 85/15, designated as PLCL15, was selected as matrix material for the preparation of the composites based on its optimized property of modulus and toughness (PLCL15 was selected from a series of blend prepared from the same PLA and PCL in a separate preliminary study by the present group). The blend (PLCL15) and composites, PLA/PCL/W (phr) in the ratio of 85/15/01, 85/15/04 and 85/15/08 designated as PLCLW1, PLCLW4 and PLCLW8 respectively, were prepared by melt blending technique using a co-rotating twin-screw extruder (Model: Haake Thermofischer Prism Eurolab 16; L/D: 40, die diameter: $2.5 \mathrm{~mm}$, screw diameter: $16 \mathrm{~mm}$ ). All compositions were processed maintaining 160 $190^{\circ} \mathrm{C}$ temperature profile in the extruder and $190^{\circ} \mathrm{C}$ at the die with a screw speed of $200 \mathrm{rpm}$. The raw materials were pre-dried at $45^{\circ} \mathrm{C}$ under vacuum for 12 hours. The strands were granulated and subsequently injection moulded at $190^{\circ} \mathrm{C}$ (model: $\mathrm{L} \& \mathrm{~T}$, Demag, PFY40-LNC 4P) to prepare $0.75 \mathrm{~mm}$ thick sheets for foaming purposes in a in house fabricated injection mold.

\subsection{Development of composites as porous scaffold}

Solid state batch foaming process was adopted to prepare microporous scaffolds from the injection moulded composite sheets. Cut samples of $4 \times 4 \times$ $0.75 \mathrm{~mm}^{3}$ sizes were used for batch foaming by using compressed $\mathrm{CO}_{2}$ as the physical blowing agent. A high pressure vessel was used as batch foaming apparatus for saturating the samples with $\mathrm{CO}_{2}$. This solid state foaming process involved basically three stages - saturation of the samples with a blowing agent to produce a polymer-solvent system, depressurization controlling phase separation developing nucleation sites and bubble growth causing expansion of the nucleated micro-bubbles in the polymer giving a foamed product. Foams in four different batches were produced using saturation pressure of $1,3,5$ and $8 \mathrm{MPa}$ for seven days. Foaming of the samples was done at $160^{\circ} \mathrm{C}$ temperature using hot glycerine bath immediately after depressurizing the pressure vessel at the rate of $1.6 \mathrm{MPa} / \mathrm{min}$. The higher foaming temperature favored uninhibited 
bubble expansion producing cells of desired sizes. Based on the morphological evaluation of the foams of different batches, the foams obtained from $3 \mathrm{MPa}$ pressure batch were optimized for further studying as scaffold by seeding osteoblast cells.

\subsection{Scanning electron microscopy (SEM)}

Cryofractured (under liquid nitrogen) surfaces of all the compositions in both foamed and unfoamed state were scanned to study phase morphology using a scanning electron microscope (Model: Carl Zeiss EVO 5O SEM, Germany) with accelerating voltage of $20 \mathrm{kV}$. Samples were gold-sputtered before scanning to dissipate the charges produced in the nonconducting polymers. SEM scans of the porous scaffolds were analyzed for cell size and immiscible PCL domain sizes in the unfoamed polymers were calculated by ImageJ software.

\subsection{Transmission electron microscopy (TEM)}

The composites were viewed in transmission mode using JEOL JEM-2100F field emission microscope. Samples, which were prepared by microtoming process as $100 \mathrm{~nm}$ thick slices from injection moulded composite specimens, were scanned using $200 \mathrm{kV}$ accelerating voltage.

\subsection{Compressive test}

Mechanical testing under compressive mode was performed in a universal testing machine (INSTRON 5582) using a static load of $100 \mathrm{kN}$ at crosshead speed of $1 \mathrm{~mm} / \mathrm{min}$ at room temperature. The test was performed transversely with respect to tensile test direction. The rectangular shaped specimens were prepared by machining injection moulded samples $\left(20 \times 20 \times 3 \mathrm{~mm}^{3}\right)$. The dimensions of each sample were fed into the Merlin software during the test and compressive modulus and strength were measured for five samples of each composition. Wet compressive test was performed as in vitro study, after keeping the samples in phosphate buffered saline (PBS) solution at $\mathrm{pH} 7.4$ under enzymatic condition (enzyme used- lysozyme) for 7 (seven) days in a shaking water bath (Julabo SW23). The samples were then taken out and wiped to remove the excess media before testing. The same testing procedure was followed with the wet samples as well.

\subsection{Contact angle measurement}

Dynamic contact angle of the polymers were measured in a KRUSS Processor Tensiometer K100 attached with KRUSS Laboratory Desktop K100 Contact Angle software, using injection moulded sheet specimen of size $20 \times 10 \times 0.75 \mathrm{~mm}^{3}$. Three specimens were tested for advancing and receding dynamic angles which have been averaged and reported in the present work.

\subsection{In vitro bioactivity study on the prepared scaffolds}

\subsubsection{Isolation of osteoblast cells}

Goat tibia bone was collected from the slaughter house and transported to the laboratory in phosphate buffered saline after getting due permission from the competent authority. Bone was cut into pieces of approximately $2-3 \mathrm{~mm}$ and washed with PBS containing antibiotics, $100 \mathrm{U} / \mathrm{mL}$ PenSrep (Lonza, Cat no.17-602E), $50 \mathrm{mg} / \mathrm{ml}$ Getamicin sulfate (Himedia, Cat No.A010) and $100 \mathrm{mg} / \mathrm{ml}$ Amphotericin B (Himedia Cat No.A011). The pieces were incubated for 7 days in Dulbecco's Modified Eagle Medium (DMEM, Cat no. CC3004.05L) on the bottom of a T25 tissue culture dish to let them adhere to the dish surface and the cells to come out of the tissue. These were cultured until sub confluence in a controlled atmosphere of $5 \% \mathrm{CO}_{2}$ and $37^{\circ} \mathrm{C}$ temperature.

\subsubsection{Culture and seeding of the cells on scaffolds}

Goat osteoblast cells were then expanded in DMEM media with $10 \%$ fetal bovine serum (Biological Industries Cat no.04-121-1A), HEPES (4-(2-hydroxyethyl)-1-piperazineethanesulfonic acid) buffer IM (Lonza, Cat no.BEA-17-737E), 100 U/mL PenSrep, $50 \mathrm{mg} / \mathrm{mL}$ Getamicin sulfate and $100 \mathrm{mg} / \mathrm{mL}$ Amphotericin B. Cells were trypsinized (Lonza, CC-5012) under sub confluent state and then used for seeding. All the polymer scaffolds were sterilized by autoclaving and pre-wet in complete medium (DMEM) for overnight prior to cell seeding. Each scaffold was seeded with $5 \cdot 10^{4}$ counts of cell and MTT assay was done after 3 and 7 days. 


\subsubsection{MTT assay}

MTT assay was used to assess metabolic activity of the osteoblasts on day 3 and day 7. Samples were dipped in 9:1 ratio of DMEM media and MTT ((3(4, 5-Dimethylthiazol-2-yl)-2, 5-diphenyltetrazolium bromide, Millipore CT0-A, USA) and incubated for 6 hours at $37^{\circ} \mathrm{C}$. The media-MTT mixture was then spun to collect insoluble formazan crystals. $1 \mathrm{~mL}$ DMSO (dimethyl sulfoxide) was used to dissolve the crystals and absorbance was checked using microplate reader (BIORAD iMark Microplate reader, USA) at $560 \mathrm{~nm}$ for 5 replicates. In addition, standard calibration curve was made by MTT assay on directly counted cells and the absorbance values were plotted against the counted cell numbers. Metabolically active cell numbers were then determined using this standard curve based on their MTT absorbance.

\subsubsection{Cell-morphology observations}

After incubating for 7 days, cell seeded scaffolds were harvested and fixed with $2.5 \%$ glutaraldehyde for 4 hours. These were then dehydrated in gradient
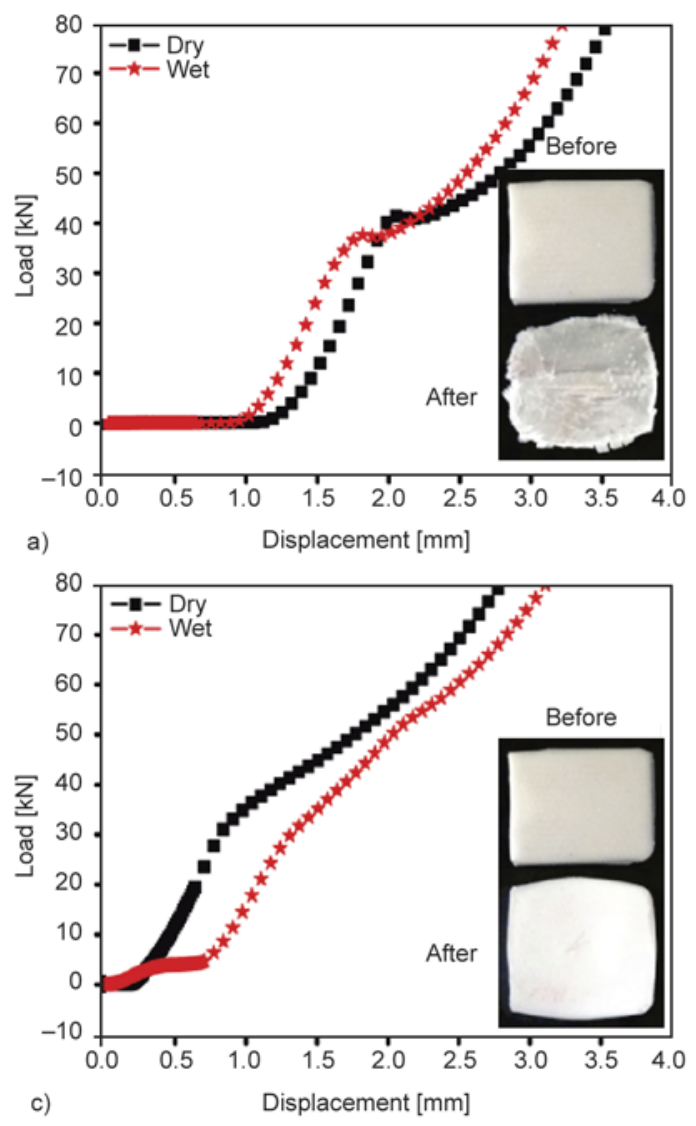

alcohol before sputter coated with gold for SEM scan.

\section{Results and discussion}

\subsection{Compressive test}

Wet compressive test was performed with an aim to mimic the materials' performance under physiological environment. The implant is expected to sustain under this harsh condition while maintaining bonhomie with the host tissue. The compressive strength of the composites could not be measured as per the ASTM D695 standard, because there was no shattering fracture and the samples were just flattened into thinner plate under applied load. The nominal stress changed steadily in two stages during the test as can be seen from Figure 1 and its inset images. Modulus of elasticity was calculated by drawing tangent at the initial linear portion of the plots and extending it to set the zero point on the strain axis, but this modulus value is indicative only, as actual values could not be determined. The results are listed in Table 2. The behavioral difference of the polymers under dry and wet test conditions is not very sig-
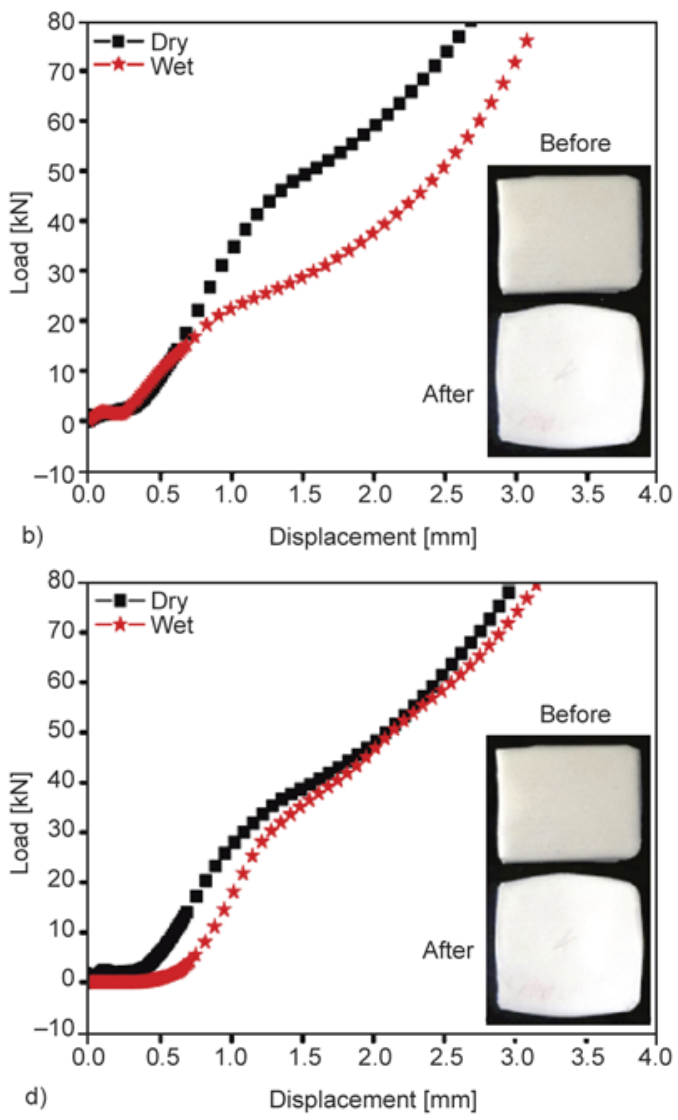

Figure 1. Plots of displacement of polymers under compressive load in both dry and wet conditions for a) PLCL15, b) PLCLW1, c) PLCLW4, and d) PLCLW8. Inset images are those of samples before and after the experiment. 
Table 2. Compressive test data under dry and wet conditions

\begin{tabular}{|l|c|c|c|c|}
\hline \multirow{2}{*}{ Composition } & \multicolumn{2}{|c|}{ Dry } & \multicolumn{2}{c|}{ Wet } \\
\cline { 2 - 5 } & $\begin{array}{c}\text { Compressive strength } \\
\text { [MPa] at ultimate load }\end{array}$ & $\begin{array}{c}\text { Elasticity modulus } \\
\text { [MPa] }\end{array}$ & $\begin{array}{c}\text { Compressive strength } \\
\text { [MPa] at ultimate load }\end{array}$ & $\begin{array}{c}\text { Elasticity Modulus } \\
\text { [MPa] }\end{array}$ \\
\hline PLCL15 & $\begin{array}{c}85.7 \pm 1.15 \\
\text { (at yield) }\end{array}$ & $\begin{array}{c}3.298 \pm 0.21 \\
\text { (at yield) }\end{array}$ & $\begin{array}{c}81.6 \pm 3.22 \\
\text { (at yield) }\end{array}$ & $\begin{array}{r}2.500 \pm 0.04 \\
\text { (at yield) }\end{array}$ \\
\hline PLCLW1 & $192.2 \pm 0.16$ & $2.755 \pm 0.18$ & $191.9 \pm 0.17$ & $2.044 \pm 0.09$ \\
\hline PLCLW4 & $185.4 \pm 0.01$ & $3.141 \pm 0.19$ & $185.2 \pm 0.01$ & $2.449 \pm 0.06$ \\
\hline PLCLW8 & $190.7 \pm 0.88$ & $2.397 \pm 0.13$ & $189.9 \pm 0.25$ & $2.674 \pm 0.21$ \\
\hline
\end{tabular}

nificant. The blend, PLCL15 got crushed at $100 \mathrm{kN}$ load and produced visible cracks. The blend shows a longer rubbery plateau at constant load value prior to the first linear rise in the plots as compared to those in the composites. It was difficult to ascertain whether the toe region of the plots was due to material property. Microacicular wollastonite helped in improvement of compressive strength of the composites on application of compressive load. Wollastonite got aligned in the flow direction during injection moulding and the machined samples were tested at the lying position. Thus this high modulus inorganic filler resisted breakage by arresting the crack propagation from filler to polymer, thereby increasing compressive strength of the polymeric composites. This reinforcing effect is more visible in PLCLW1 than the other composites (PLCLW4 and PLCLW8) that might be due to filler agglomeration in these. Similar kind of result was reported by Javni et al. [33] where micro silica filler improved compressive strength of the polymer at lower loading whereas, reverse occurred at higher loading.

The composites' compressive strength at ultimate load is calculated and as can be seen from Table 2, the property of the composites did not deteriorate much under wet conditions as compared to the blend thereby proving better resistance of the composites towards the surrounding environment.

\subsection{Scanning electron microscopy (SEM) of unfoamed composites}

Immiscible phase morphology is clearly visible in all compositions in SEM scans of the polymers (Figure 2). The minor phase, PCL remains as globules with distinct phase boundary within the PLA matrix. The immiscible PCL domain sizes in the polymers are calculated by image processing software and this domain size in the blend is bigger than that in the composites as seen from Table 3. Thus, presence of the filler causes reduction in the

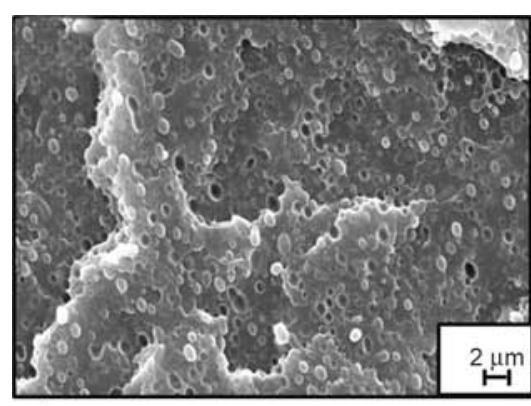

a)

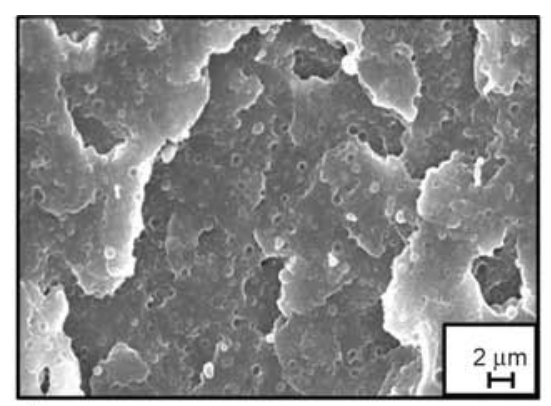

b)

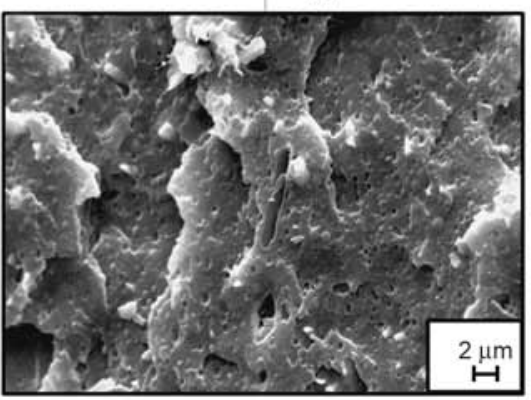

d)

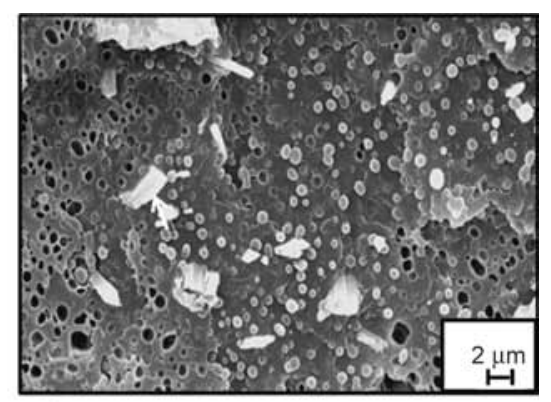

c)

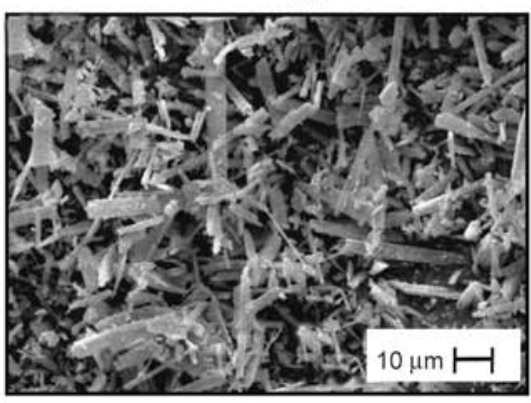

e)

Figure 2. SEM images of cryofractured surfaces of a) PLCL15, b) PLCLW1, c) PLCLW4, d) PLCLW8 and e) acicular W-powder 
PCL globule sizes. The PCL domain size reduction in the composites due to the rigid inorganic filler addition may be attributed to changed rheological properties in the polymers as compared to that of the blend. The shearing force experienced by PCL during extrusion process is different in the presence of the filler. It has been reported that the immiscible phase morphology changes in the presence of a filler and it varies with mixing time as well which has been said to be 'kinetic controlled' [34].

Wollastonite, the third component of the composites, is partially visible showing mostly its tip with distinct boundaries. Increasing presence of the filler in the polymer can be seen with increasing wollastonite content in Figure 2b, 2c and 2d containing 1, 4 and $8 \mathrm{phr}$ of wollastonite respectively. Dispersion of the filler in the composites is quite uniform, and these are oriented mostly in the flow direction due to which only the tip of the fillers could be seen. Figure 2e shows the needle shaped fillers' morphology with average length of 14.9 micron and diameter of 3.33 micron as measured using SMART SEM software attached with the SEM microscope.

\subsection{Transmission electron microscopy (TEM)}

The microtomed slices of the composites were scanned in transmission mode and the images are shown in Figure 3. The individual spherical entities confirm circular cross-section of the filler, and the distribution of the filler in the PLA/PCL matrix sys- tem is quite uniform in PLCLW1 and PLCLW4 compositions. But incorporation of higher amount of wollastonite causes agglomeration indicating better prevalence of filler-filler interaction than the polymer-filler system. The visible morphology of the wollastonite in the images re-establishes the fact that these are oriented in the flow direction and the findings of the mechanical tests can be justified.

\subsection{Contact angle measurement}

Wettability of a material is one of the crucial factors for determining the suitability of its use as biomedical implant. Increasing hydrophilicity of an implant improves polymer-bone adhesion that helps in faster regeneration of damaged tissues in vivo. Being hydrophobic, organic polymers usually lack this adhesion that slows down the tissue regeneration process. Wollastonite reduced the contact angle in the composites, thereby indicating enhanced wettability and improved scaffold-body cell attachment. The hydrophilicity is said to be the deciding factor in scaffold degradation and the surface morphology of the scaffold plays a significant role in degradation. The contact angle of wollastonite is reported as $0^{\circ}$ and it is established already in other polymers as improving hydrophilicity [35].

Dynamic contact angle measurement shows that PLCLW8, with maximum filler content, has lowest advancing contact angle as shown in Table 3. Similar trend can also been seen in receding contact

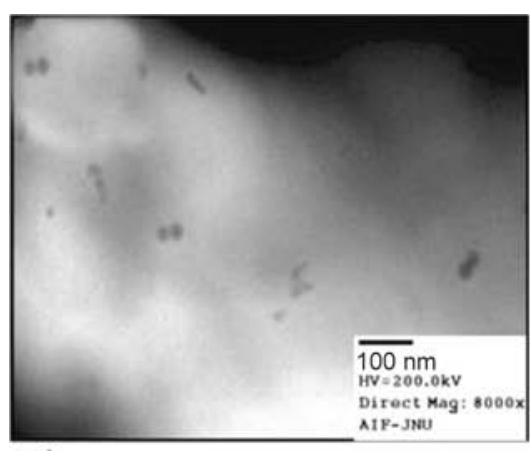

a)

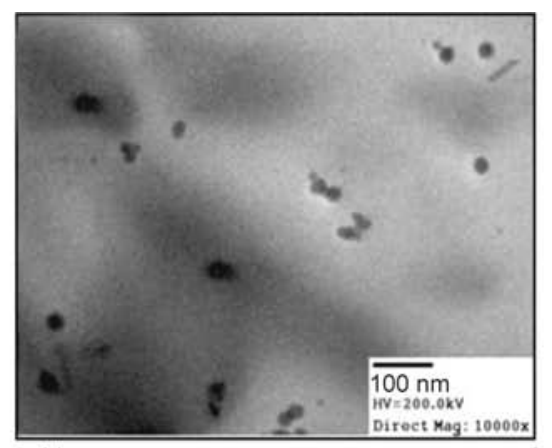

b)

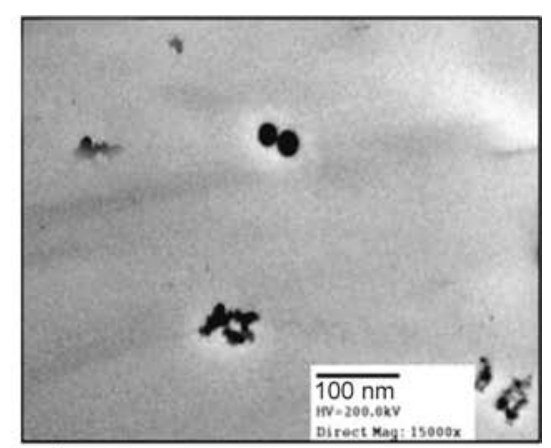

c)

Figure 3. TEM images of the microtomed samples of composites a) PLCLW1, b) PLCLW4 and c) PLCLW8

Table 3. PCL domain size, dynamic contact angle parameters, foam morphological parameters and MTT assay data

\begin{tabular}{|c|c|c|c|c|c|c|c|c|}
\hline \multirow{2}{*}{ Sample } & \multirow{2}{*}{$\begin{array}{c}\text { PCL domain size } \\
\text { (unfoamed) } \\
{[\mu \mathrm{m}]}\end{array}$} & \multirow{2}{*}{$\begin{array}{l}\mathrm{ACA}^{*} \\
{[\mathrm{deg}]}\end{array}$} & \multirow{2}{*}{$\begin{array}{l}\text { RCA }^{*} \\
{[\text { deg] }}\end{array}$} & \multirow{2}{*}{$\begin{array}{c}\text { Hysteresis } \\
\text { [deg] }\end{array}$} & \multirow{2}{*}{$\begin{array}{c}\text { Cell } \\
\text { diameter } \\
{[\mu \mathrm{m}]}\end{array}$} & \multirow{2}{*}{$\begin{array}{l}\text { Cell density } \\
\text { [cell/cc] }\end{array}$} & \multicolumn{2}{|c|}{ Number of cell (counts) } \\
\hline & & & & & & & Day 3 & Day 7 \\
\hline PLCL15 & $1.1 \pm 0.30$ & 80.0 & 57.2 & 22.8 & $6.1 \pm 1.70$ & $9.4 \cdot 10^{12}$ & 20000 & 52600 \\
\hline PLCLW1 & $0.8 \pm 0.05$ & 77.0 & 51.7 & 25.3 & $5.4 \pm 0.82$ & $11.7 \cdot 10^{12}$ & 35080 & 76000 \\
\hline PLCLW4 & $0.6 \pm 0.08$ & 75.2 & 47.1 & 28.2 & $5.5 \pm 0.79$ & $10.9 \cdot 10^{12}$ & 33025 & 252634 \\
\hline PLCLW8 & $0.7 \pm 0.09$ & 72.1 & 44.3 & 27.7 & $8.3 \pm 0.52$ & $3.5 \cdot 10^{12}$ & 62000 & 356900 \\
\hline
\end{tabular}

${ }^{*}$ ACA: advancing contact angle, RCA: receding contact angle 
angle values that indicate de-wettability of the materials. The hysteresis indicates the surface roughness or chemical inhomogeinity in the samples. Increasing hysteresis value with increased filler content (Table 3), refers to increased variation of surface property along the contact line. The contact line of the polymer during advancement and receding decides the kind of interaction between the liquid and polymer. Decreasing contact angle value indicates increasing contact area thereby enhancing polymertissue adhesion.

\subsection{Characterization of the foams (SEM)}

Nucleation and cell expansion in a polymer with higher $T_{\mathrm{g}}$ value takes place not during depressurization, but in the high temperature foaming stage [36]. PLA has $T_{\mathrm{g}}$ much above the room temperature (around $60^{\circ} \mathrm{C}$ ) indicating that diffusion out of the solvent causing nucleation and expansion in the current system occurred at the foaming temperature. Microcells are produced throughout the compositions as found from cell size and cell density calculation (Table 3 ) and these cellular structures are supposed to be supportive towards cell growth in biomedical scaffolding applications. The microcellular morphology of the composites is visibly different from the blend foam in terms of cell size distribution (Figure 4). With increasing filler content, cell diameter increased which correspondingly reduced cell density and PLCLW8 composition produced microcells larger than the blend itself giving mini-

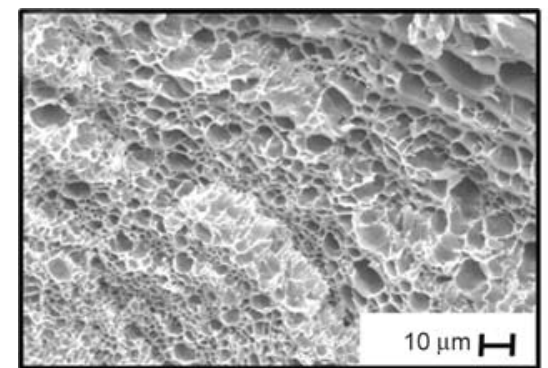

a)

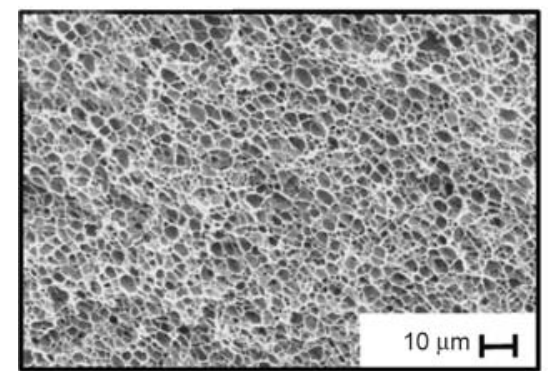

c) mum cell density value. This might be due to filler agglomeration at higher loading that reduces the bubble nucleation capability of the polymer. The inhomogeneity in the polymers is created by introducing immiscible domains of PCL and acicular inorganic filler. The blend also produces microcellular foams, but the presence of the filler adds uniformity in cell distribution because of lowered activation energy required for bubble nucleation at the interphases.

\subsection{Cellular adhesion studies on the scaffold constructs}

The present study compares the suitability of the polymeric scaffold constructs for cell culture with osteoblast cells. Cell proliferation and morphology of the cells were studied by doing MTT assay and SEM scan. Standard plot for MTT assay (inset plot of Figure 5) was prepared by running a blank experiment where cells were seeded in the media without the scaffold. The growing number of cells was counted for two different incubation periods i.e. 3 and 7 days by correlating absorbance by the scaffold with that in the standard plot and the result is shown in Figure 5. MTT assay result of the scaffolds shows that after 3 and 7 days of culture, the number of metabolically active cell is highest in PLCLW8 followed by PLCLW4 and PLCLW1 while remaining minimum in PLCL15 blend scaffold (Table 3). These results indicate that composites with $\mathrm{CaSiO}_{3}$ filler are able to support the growth and
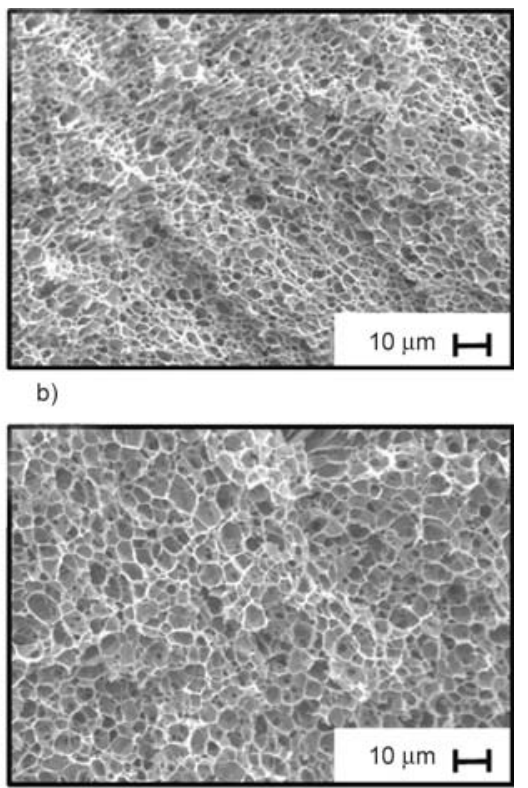

d)

Figure 4. SEM images of cryofractured surfaces of the foams a) PLCL15, b) PLCLW1, c) PLCLW4 and d) PLCLW8 


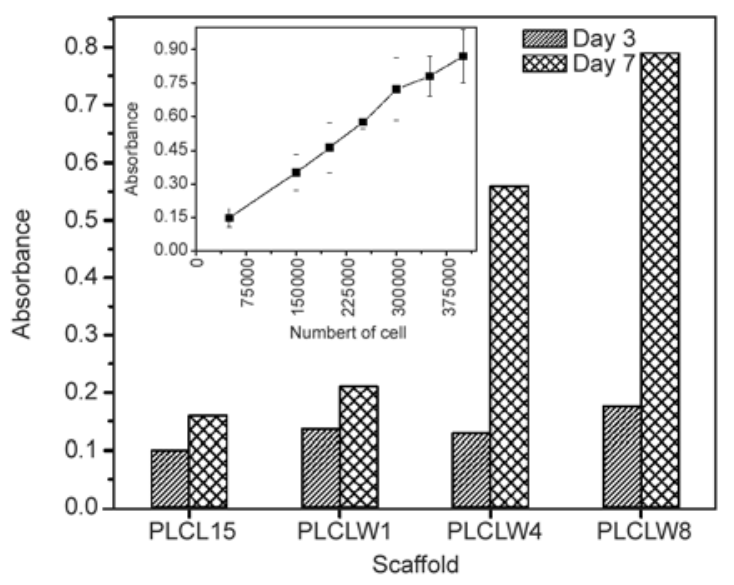

Figure 5. MTT assay absorbance data of the cell seeded scaffolds. The inset plot shows standard MTT curve for osteoblast cells.

proliferation of osteoblast cells more than the unfilled polymer (PLCL15). The enhanced proliferation in the composites as compared with the blend sample may be attributed to the alkaline ions released by the filler in contact with the culture media. It is reported that calcium silicate filler releases calcium and silicon ions in such media that maintains the media $\mathrm{pH}$ while improving cell adhesion to the scaffolds [37]. In SEM images (Figure 6) of the cell cultured scaffolds, the cells are characterized by a typical fibrob-

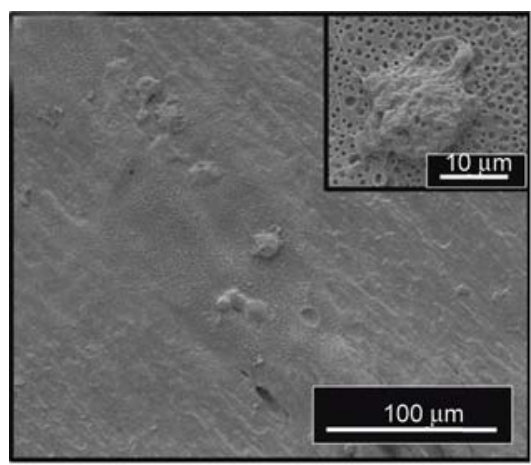

a)

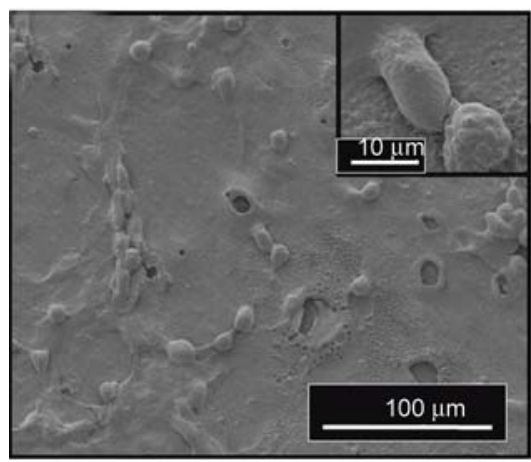

c) last-like morphology. In vivo, such morphology for osteoblastic-lineage cells is found only if osteoblasts are resting and covering inactive bone surfaces and bone lining cells. In the controlled blend composition, irregularly-shaped osteoblast with less cell count is seen. The MTT assay finding is further supported by the SEM scans showing more cell counts on the surfaces with increasing filler content. PLCLW8 scaffold construct having maximum filler content is fully layered by the osteoblast cells which are interconnected with each other as compared with PLCLW1 composition showing cell lining in a group manner and thus, enhanced bioactivity of the calcium silicate filler can be found in PLCLW8.

\section{Conclusions}

The current report is a comprehensive one starting from selecting the raw materials to the cell viability study on the prepared foams. The enhancement in mechanical properties of the composites along with favored cell growth on the scaffold constructs is evident from the experimental work. Wollastonite is a highly potential bioactive filler to induce cell attachment, differentiation and proliferation by inhibiting the deteriorating effects of acidic by-

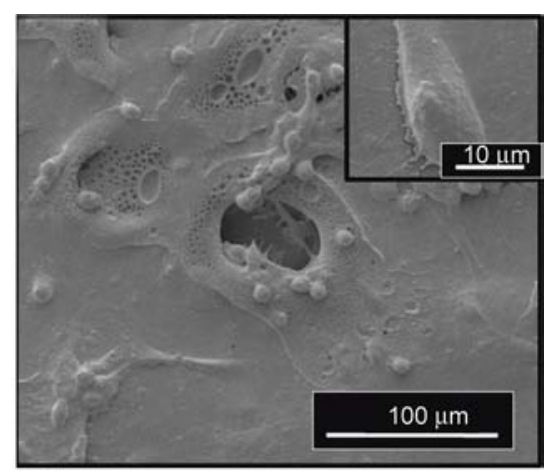

b)

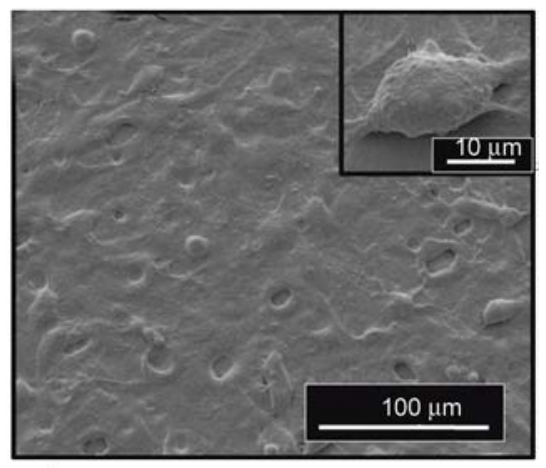

d)

Figure 6. SEM scans of the osteoblast grown scaffolds after 7 days incubation period, a) PLCL15, b) PLCLW1, c) PLCLW4 and d) PLCLW8. The inset images show the fibroblast like morphology of individual cell at higher magnification. 
products of biopolymers and releasing alkaline ions, thereby maintaining the $\mathrm{pH}$ of the surrounding environment of the damaged tissues at an optimum level for faster regeneration of the cells. The outcome of the present study is summarized below,

- Surface morphology of the unfoamed polymers established immiscible behavior of the three components in the composites.

- Compressive test reaffirmed the usability of the prepared polymers for in vivo application.

- Addition of wollastonite improved hydrophilicity of the polymers that helped in better implanttissue adhesion.

- Presence of the filler improved foamability of the matrix by introducing heterogeneous nucleation sites in the polymers and producing uniform microcells.

- The biocompatibility study of the foamed constructs as scaffold proved that the $\mathrm{CaSiO}_{3}$ filler helped in osteoblast cell lining throughout the scaffold surface that increased with increasing filler content in comparison to the controlled blend scaffold.

\section{References}

[1] Murugan R., Ramakrishna S.: Development of nanocomposites for bone grafting. Composites Science and Technology, 65, 2385-2406 (2005). DOI: $10.1016 /$ j.compscitech.2005.07.022

[2] Ramakrishna S., Mayer J., Wintermantel E., Leong K. W.: Biomedical applications of polymer-composite materials: A review. Composites Science and Technology, 61, 1189-1224 (2001). DOI: 10.1016/S0266-3538(00)00241-4

[3] Broz M. E., VanderHart D. L., Washburn N. R.: Structure and mechanical properties of poly(D,L-lactic acid)/ poly(E-caprolactone) blends. Biomaterials, 24, 41814190 (2003).

DOI: $10.1016 / \mathrm{S} 0142-9612(03) 00314-4$

[4] Sarazin P., Li G., Orts W. J., Favis B. D.: Binary and ternary blends of polylactide, polycaprolactone and thermoplastic starch. Polymer, 49, 599-609 (2008). DOI: $10.1016 /$ j.polymer.2007.11.029

[5] Weir N. A., Buchanan F. J., Orr J. F., Farrar D. F., Boyd A.: Processing, annealing and sterilisation of poly-Llactide. Biomaterials, 25, 3939-3949 (2004). DOI: $10.1016 /$ j.biomaterials.2003.10.076

[6] Di Lorenzo M. L.: Crystallization behavior of poly(Llactic acid). European Polymer Journal, 41, 569-575 (2005).

DOI: 10.1016/j.eurpolymj.2004.10.020
[7] Rezgui F., Swistek M., Hiver J. M., G’Sell C., Sadoun T.: Deformation and damage upon stretching of degradable polymers (PLA and PCL). Polymer, 46, 73707385 (2005).

DOI: 10.1016/j.polymer.2005.03.116

[8] Chen C-C., Chueh J-Y., Tseng H., Huang H-M., Lee SY.: Preparation and characterization of biodegradable PLA polymeric blends. Biomaterials, 24, 1167-1173 (2003).

DOI: $10.1016 / \mathrm{S} 0142-9612(02) 00466-0$

[9] Liao H-T., Wu C-S.: Preparation and characterization of ternary blends composed of polylactide, poly $(\varepsilon-$ caprolactone) and starch. Materials Science and Engineering: A, 515, 207-214 (2009).

DOI: $10.1016 /$ j.msea.2009.03.003

[10] López-Rodríguez N., López-Arraiza A., Meaurio E., Sarasua J. R.: Crystallization, morphology, and mechanical behavior of polylactide/poly( $\varepsilon$-caprolactone) blends. Polymer Engineering and Science, 46, 1299-1308 (2006).

DOI: $10.1002 /$ pen.20609

[11] Rasal R. M., Janorkar A. V., Hirt D. E.: Poly(lactic acid) modifications. Progress in Polymer Science, 35, 338-356 (2010).

DOI: $10.1016 /$ j.progpolymsci.2009.12.003

[12] Carrasco F., Pagès P., Gámez-Pérez J., Santana O. O., Maspoch M. L.: Processing of poly(lactic acid): Characterization of chemical structure, thermal stability and mechanical properties. Polymer Degradation and Stability, 95, 116-125 (2010).

DOI: 10.1016/j.polymdegradstab.2009.11.045

[13] Todo M., Park S-D., Takayama T., Arakawa K.: Fracture micromechanisms of bioabsorbable PLLA/PCL polymer blends. Engineering Fracture Mechanics, 74, 1872-1883 (2007).

DOI: 10.1016/j.engfracmech.2006.05.021

[14] Li H., Chang J.: Preparation and characterization of bioactive and biodegradable Wollastonite/poly(D,Llactic acid) composite scaffolds. Journal of Materials Science: Materials in Medicine, 15, 1089-1095 (2004). DOI: 10.1023/B:JMSM.0000046390.09540.c2

[15] Kokubo T.: Apatite formation on surfaces of ceramics, metals and polymers in body environment. Acta Materialia, 46, 2519-2527 (1998). DOI: $10.1016 / \mathrm{S} 1359-6454(98) 80036-0$

[16] Wang M.: Developing bioactive composite materials for tissue replacement. Biomaterials, 24, 2133-2151 (2003).

DOI: 10.1016/S0142-9612(03)00037-1

[17] Kothapalli C. R., Shaw M. T., Wei M.: Biodegradable HA-PLA 3-D porous scaffolds: Effect of nano-sized filler content on scaffold properties. Acta Biomaterialia, 1, 653-662 (2005).

DOI: $10.1016 /$ j.actbio.2005.06.005 
[18] Wan X., Chang C., Mao D., Jiang L., Li M.: Preparation and in vitro bioactivities of calcium silicate nanophase materials. Materials Science and Engineering: C, 25, 455-461 (2005).

DOI: $10.1016 / \mathrm{j} . \mathrm{msec} .2004 .12 .003$

[19] Zhang N., Molenda J. A., Fournelle J. H., Murphy W. L., Sahai N.: Effects of pseudowollastonite $\left(\mathrm{CaSiO}_{3}\right)$ bioceramic on in vitro activity of human mesenchymal stem cells. Biomaterials, 31, 7653-7665 (2010).

DOI: $10.1016 /$ j.biomaterials.2010.06.043

[20] Wu C., Zhang Y., Fan W., Ke X., Hu X., Zhou Y., Xiao $\mathrm{Y}$.: $\mathrm{CaSiO}_{3}$ microstructure modulating the in vitro and in vivo bioactivity of poly(lactide-co-glycolide) microspheres. Journal of Biomedical Materials Research Part A, 98, 122-131 (2011). DOI: $10.1002 / \mathrm{jbm} . \mathrm{a} .33092$

[21] Li X., Shi J., Zhu Y., Shen W., Li H., Liang J., Gao J.: A template route to the preparation of mesoporous amorphous calcium silicate with high in vitro boneforming bioactivity. Journal of Biomedical Materials Research Part B: Applied Biomaterials, 83, 431-439 (2007).

DOI: $10.1002 / \mathrm{jbm} . b .30813$

[22] Lim Y-M., Gwon H-J., Shin J., Jeun J. P., Nho Y. C.: Preparation of porous poly( $\varepsilon$-caprolactone) scaffolds by gas foaming process and in vitro/in vivo degradation behavior using $\gamma$-ray irradiation. Journal of Industrial and Engineering Chemistry, 14, 436-441 (2008). DOI: 10.1016/j.jiec.2008.01.019

[23] Wei J., Chen F., Shin J-W., Hong H., Dai C., Su J., Liu C.: Preparation and characterization of bioactive mesoporous wollastonite - polycaprolactone composite scaffold. Biomaterials, 30, 1080-1088 (2009). DOI: $10.1016 /$ j.biomaterials.2008.10.046

[24] Sung H-J., Meredith C., Johnson C., Galis Z. S.: The effect of scaffold degradation rate on three-dimensional cell growth and angiogenesis. Biomaterials, 25, 5735-5742 (2004).

DOI: $10.1016 /$ j.biomaterials.2004.01.066

[25] Sauceau M., Fages J., Common A., Nikitine C., Rodier E.: New challenges in polymer foaming: A review of extrusion processes assisted by supercritical carbon dioxide. Progress in Polymer Science, 36, 749-766 (2011). DOI: 10.1016/j.progpolymsci.2010.12.004

[26] Fujimoto Y., Ray S. S., Okamoto M., Ogami A., Yamada K., Ueda K.: Well-controlled biodegradable nanocomposite foams: From microcellular to nanocellular. Macromolecular Rapid Communications, 24, 457-461 (2003).

DOI: $\underline{10.1002 / \text { marc. } 200390068}$
[27] Matuana L. M., Faruk O., Diaz C. A.: Cell morphology of extrusion foamed poly(lactic acid) using endothermic chemical foaming agent. Bioresource Technology, 100, 5947-5954 (2009). DOI: $10.1016 /$ j.biortech.2009.06.063

[28] Yu L., Liu H., Dean K., Chen L.: Cold crystallization and postmelting crystallization of PLA plasticized by compressed carbon dioxide. Journal of Polymer Science Part B: Polymer Physics, 46, 2630-2636 (2008). DOI: $10.1002 /$ polb.21599

[29] Kazarian S. G., Vincent M. F., Bright F. V., Liotta C. L., Eckert C. A.: Specific intermolecular interaction of carbon dioxide with polymers. Journal of the American Chemical Society, 118, 1729-1736 (1996). DOI: $10.1021 /$ ja950416q

[30] Nalawade S. P., Picchioni F., Marsman J. H., Janssen L. P. B. M.: The FT-IR studies of the interactions of $\mathrm{CO}_{2}$ and polymers having different chain groups. The Journal of Supercritical Fluids, 36, 236-244 (2006). DOI: $10.1016 /$ j.supflu.2005.06.005

[31] Lee S. T., Ramesh N. S.: Polymeric foams: Mechanisms and materials. CRC Press, Boca Raton (2004).

[32] Zhao S., Zhou Z., Wu J., Wang S., Guo X., Zhang Q.: Preparation and characterization of a novel hydroxyapatite-wollastonite/silk fibroin composite. Journal of Composite Materials, 46, 1571-1581 (2012).

DOI: $10.1177 / 0021998311421040$

[33] Javni I., Zhang W., Karajkov V., Petrovic Z. S., Divjakovic V.: Effect of nano- and micro-silica fillers on polyurethane foam properties. Journal of Cellular Plastics, 38, 229-239 (2002).

DOI: 10.1177/0021955x02038003139

[34] Zhang Q., Yang H., Fu Q.: Kinetics-controlled compatibilization of immiscible polypropylene/polystyrene blends using nano- $\mathrm{SiO}_{2}$ particles. Polymer, 45, 19131922 (2004).

DOI: $10.1016 /$ j.polymer.2004.01.037

[35] Li H., Chang J.: Fabrication and characterization of bioactive wollastonite/PHBV composite scaffolds. Biomaterials, 25, 5473-5480 (2004).

DOI: $10.1016 /$ j.biomaterials.2003.12.052

[36] Matuana L. M., Faruk O.: Effect of gas saturation conditions on the expansion ratio of microcellular poly (lactic acid)/wood-flour composites. Express Polymer Letters, 4, 621-631 (2010). DOI: $10.3144 /$ expresspolymlett.2010.77

[37] Xu L., Xiong Z. C., Yang D., Zhang L. F., Chang J., Xiong C. D.: Preparation and in vitro degradation of novel bioactive polylactide/wollastonite scaffolds. Journal of Applied Polymer Science, 114, 3396-3406 (2009). DOI: $\underline{10.1002 / a p p .28475}$ 